\title{
The development of anger management program based on acceptance and commitment therapy for youth taekwondo players
}

\author{
Duksun Chang', Seunghyun Hwang',* \\ 'Department of Physical Education, Korea National Sport University, Seoul, Korea \\ ${ }^{2}$ Department of Sport Science, Korea Institute of Sport Science, Seoul, Korea
}

This study aimed to develop an intervention program based on acceptance and commitment therapy (ACT) for youth taekwondo players. Eight sessions of the ACT program were provided to nine youth taekwondo players. The content analysis was conducted for the activities, activity sheets, assignments, and program evaluations. First of all, the results showed that the ACT program changed the participants' diverse psychological inflexibility a flexible and value-oriented state, which was supported by their positive mood changes after each session. Secondly, 'walking meditation,' 'a bus driver and a passenger role play,' and 'writing a letter to the self' were positively evaluated according to the analysis on the feedbacks and evaluations on each session and activity. Lastly, overall evaluation on the ACT program indicated that there were changes in a positive attitude, thoughts, and feelings /anger and irritation) toward taekwondo. The most memorable activities were 'eating meditation, 'breath-counting meditation,' and 'welcoming the beggar' exercise. These results suggest that an intervention program based on the ACT may have a positive impact on anger management for youth.

Keywords: Acceptance and commitment therapy, Taekwondo, Anger management

\section{INTRODUCTION}

Anger is a natural and general human emotion. Anger is the result of cognitive process through individual's evaluation and interpretation, as well as an internal emotion that expresses one's aggressiveness to a particular target with physical and verbal aggression (Wilkowski et al., 2010). Aggression appears to reduce the anger under the circumstance of threat and frustration (Wilkowski and Robinson, 2008).

Elementary school students show a lack of judgment on circumstances, and tend to judge based on their emotion rather than rationality. Sometimes, they demonstrate aggressive actions. The main feature of aggressive children's behaviors is an angry expression in an immature, immediate, and nonverbal way with a meager social problem-solving skill. Aggressive children have difficulties in learning and adapting to school (Chen et al., 1995).
Because aggression in childhood continuously develops stably to adolescence and adulthood, aggression in preadolescence is a predictor of aggression in future and other negative outcomes in the adolescent period (Huesmann and Eron, 1984). Huesmann and Eron (1984)'s longitudinal study traced the aggression level of children at 8 years old until they were aged 30, which was highly related to the aggressive deposition, criminal behavior, spousal abuse, punitive parenting, and their children's aggression. It provides empirical evidence that the aggressive deposition in childhood continued through adulthood. Therefore, efforts to manage aggressive deposition in the childhood are required (Greco and Hayes, 2008; Rempel, 2012), and effective anger management programs are necessary in order to regulate aggression. Currently in Korea, as the age of taekwondo learners among student population is getting younger, most of them are elementary school students. Taekwondo training during the elementary school period
${ }^{*}$ Corresponding author: Seunghyun Hwang (iD http://orcid.org/0000-0002-2800-6418 Department of Sport Science, Korea Institute of Sport Science, 727 Hwarang-ro, Nowon-gu, Seoul 01794, Korea

Tel: +82-2-970-9589, Fax: +82-2-970-9686, E-mail: hwangseung78@gmail.com Received: December 20, 2016 / Accepted: March 29, 2017
This is an Open Access article distributed under the terms of the Creative Commons Attribution Non-Commercial License (http://creativecommons.org/licenses/by-nc/4.0/) which permits unrestricted non-commercial use, distribution, and reproduction in any medium, provided the original work is properly cited. 
has positive effects on physical, cognitive, emotional, and social development (Lee and Song, 2006). Taekwondo has positive influences on trainees' psychological constructs such as willpower (Kim, 2005), concentration (Kim and Kim, 2000), and self-regulation (Lakes and Hoyt, 2004). Also, taekwondo trainees have a lower acculturative stress level than non-trainees, and cope effectively with it (Kim et al., 2012). Another study on taekwondo elementary school trainees in the U.S. pointed out that taekwondo positively developed sociability and mental health (Lee, 2010). Han and Son (2003) proved how the taekwondo training intensity affected hostility and victimization as showing the negative relationship between the taekwondo level and the hostility and victimization.

Meanwhile, several studies suggested that a systematic cognitive behavior training program had an effect on reducing depression and aggressive actions, and managing anger (Beck and Fernandez, 1998; Sukhodolsky et al., 2004). Meditation focusing on mental stability eliminated distraction and negative emotions, and helped children develop the ability to observe themselves with a receptive attitude and decrease negative emotions such as anger (Keng et al., 2011).

Meditation became popular among counselors and clinical psychologists since Benson (1975) applied it to the cardiac disease therapy. acceptance and commitment therapy (ACT) is a new trend that combines cognitive treatments and mindfulness meditation in order to discard empirical evasion, and to learn acceptance. The empirical evasion is considered as a main cause of many psychological disorders (Hayes and Storsahl, 2004; Hayes et al., 1999).

ACT is regarded as a third trend of the cognitive behavior therapy, which is based on functional contextualism, a kind of pragmatism (Luoma et al., 2007). The core components of contextualism are attention on a whole case, sensitivity to the contextual role for understanding the case's characteristics and function, and a clear understanding on the goal of the pragmatic truth standard. Another ACT's fundamental factor is psychological inflexibility, which means a disability to regulate actions to accomplish the desired goal (c.f., changing behavior and endure if change and endurance is necessary). The ACT model explains that psychological inflexibility is a result from the narrowed reaction range through the process of cognitive fusion and empirical evasion by language (Greco and Hayes, 2008).

ACT tries to maintain psychological flexibility by the six core principles; acceptance, cognitive diffusion, self as context, being present, values, and committed action. These core principles have a positive effect on psychological flexibility as they are interconnected and interacted with each other.
Recently, empirical studies have proven that ACT is effective not only for adults, but also for children and adolescents. ACT helped increase the school attendance rate of possible drop-outs (Moore et al., 2003), and improve the life quality of pediatric patients along with increasing their school attendance rate (Wicksell et al., 2005). Nonoperant control strategies were very effective for anorexia female students (Heffner et al., 2002). Like so, ACT's therapeutic and educational intervention to children and adolescents who suffer from negative emotions has proven as an effective way.

In addition, as a result of abdominal breathing and meditation programs, ACT played an effective mediator for taekwondo players to reduce stressors related to athletic performance (Ahn, 2003). Song and Son (2011) examined that ACT could decrease anger and stress of college students, in which psychological receptivity was meaningfully improved, and aggression and a secondary anger thought were noticeably decreased, whereas a primary anger and the trait anger were not influenced by the program. This results implied the effectiveness of ACT program on anger related matters.

As for a group therapy, not an individual counseling, Zettle et al. (2011) found that both the cognitive therapy group and the ACT group showed improvement in anger management, which demonstrated that the group therapy was effective as much as the individual therapy. Children in elementary school are in a significant period for emotional development. Thus, taekwondo is such a competitive and aggressive sport, and puts players in stressful situation. Therefore, this study was to apply ACT intervention program) to the elementary school Taekwondo athletes in order to decrease anger and anxiety caused by training and competitions.

\section{MATERIALS AND METHODS}

\section{Participants}

Nine taekwondo players at the Soo Sung elementary school in Seoul participated in this study. Purposeful sampling was used. The demographic background was as follows: their average grade was 3.44; their average age was 9.89 years old; the average start age of taekwondo was 8.11 years old; their training period was 2.78 years; and their average years as an elite athlete was 1.56 years.

\section{Research process and analysis}

Every day from 13:30 p.m. to 15:00 p.m. during the winter training period, the elementary taekwondo players went through eight sessions of mindfulness ACT. Pre- and postevaluations were not included in the eight sessions of the program. First, in the pretest, introducing the program, cultivating of the psychological 
Table 1. Mindfulness acceptance commitment therapy program

\begin{tabular}{lll}
\hline \multicolumn{1}{c}{ Session } & \multicolumn{1}{c}{ Subject } & \multicolumn{1}{c}{ Goal } \\
\hline 1st & Creative helplessness & To understand the ACT for anger acceptance \\
2nd & Attention and willingness & To understand consequences that controlling anger leads to psychological evasion and escape \\
3rd & Cognitive de-fusion and awareness & To understand language of anger and irritation and the function of cognition \\
4th & Self-observation & To contact with the present moment by observing thoughts and experiences about anger and irritation \\
5th & Contacting with the present moment & To experience the present moment as it is by staying away from thoughts and emotions about anger \\
6th & Understanding commitment & To accept and admit the anger through 'welcoming the-beggars' activity \\
7th & Choosing value & To understand the goal as Taekwondo player and the importance of value based life while in anger \\
8th & Finding a valuable life & To pursue valuable life by clarifying value in the major parts of life \\
Common activity & A presentation lecture in each session took place to explain each session's goal and activities. \\
& & Feedback in each session was received about their experiences, emotions, and feelings of doing the activities. \\
& & Affection meditation was used at the end of each session to spread affection to themselves and others.
\end{tabular}

ACT, acceptance commitment therapy.

environment for group cohesiveness, and filling research consent took place. At the posttest, the program evaluations were delivered. Activity papers, each session assignment, and program evaluations were analyzed to test the effectiveness of the program.

\section{Mindfulness ACT}

Based on the previous studies and literature about ACT, a psychological acceptance and acceleration program was constructed. The program combined perspectives of mindfulness and ACT. All the sessions were modified to an elementary level. Mindfulness meditation at the beginning and end of each session was conducted to help participants concentrate on the program, and evoke interest. Table 1 provides a brief summary of the eight sessions.

\section{Mindfulness ACT evaluation}

In order to evaluate the effect of mindfulness ACT on anger management, the participants recorded their feelings and emotions, and evaluated the experience of the activities each time. Also, after finishing all eight sessions, an overall evaluation about the program was conducted.

\section{RESULTS}

\section{Introduction of session activities and analysis of activity sheets}

\section{First session activity}

The goal of the first session was to understand the traits of ACT. A brief introduction was demonstrated with meditation photos. Subsequently, eating orange meditation took place to appreciate their participation, and increase their interests in mindfulness meditation. Eating orange meditation was enough to generate curiosity. It also helped the participants realizing everyday life. For the acceptance and commitment, we compared self-frustration, disappointments and desperation caused by the taekwondo training or matches with a tug of war. In other words, playing at a tug of war was explained with examples such as trying to play a computer game when it was impossible, training against their will, evading despite of their own faults, thinking sports was the only thing that I had to do, and regretting the past etc. by doing so, various control strategies were introduced as well as the uselessness of the strategies.

\section{Second session activity}

The goal of the second session was to understand that controlling anger could result in evasion and escape, followed by inevitable consequences. In order to accomplish the goal, gradual relaxation of arms, legs, trunk, and face was practiced. Also, the meditation posture and breath-counting meditation, which helped the participants feel inhaling and exhaling, was introduced. Concentration training called 'Kim's game,' which showed various items first, and then let them write down what they remembered, was conducted. In order to show how hard it was to maintain or control concentration with afterimages and inconvenience for their memory, 'Suppressing the white bear' was practiced. This helped the participants understand the hardness of controlling and Willingness. Also, the importance of breathing was emphasized by breath-holding activity. Lastly, they named their anger and wrote a letter to their anger to experience and be aware of anger. As a result, they expressed their desire for anger-control.

\section{Third session activity}

The goal of the third session was to understand the cognitive limit of language, for which we let them experience cognitive dif- 
fusion and mindfulness. First of all, mindfulness by sitting meditation took place with focusing on the palm to feel energy on it, through which they learned that concentration helped feel what they could not feel without concentration. They also realized that interests and concentration worked for mind. Also, cognitive movement was applied by walking-meditation. In this activity, they noticed their movements; lifting a hind leg followed by thigh muscle moving forward, landing the foot on the ground, stretching the body forward in the air, moving hands to keep the balance. In the walking stage, their movements were classified into three steps as focusing on their foot on the ground, (a) lifting required lifting a right foot, (b) forward included walking forward, and (c) lay down indicated putting the foot down. One confuses linguistic matters with its psychological contents when the acceptance and commitment is predominated by language analogy. In other words, the gap between thought and speech is narrower, and the contextured life seems real. For instance, if someone thinks he/ she is useless, the thought and the fact are combined unconsciously, which can be compared to an effect of acupuncture. The goal of this practice was to defuse the difficult taekwondo skills, pains of training, sadness of defeat, anxiety of competition from their related thoughts, words, and behavior.

In the two sides of the coin activity, the participants filled out one side of a paper with their opinions about the taekwondo training, difficulties of training procedures, and complaints for their coaches. On the other side, they wrote their desired dreams for taekwondo. Then, they folded the paper, and the counselor stole it from them, and informed that the pain had gone, but at the same time, their desired dreams were lost as well. Therefore, this game taught them that accomplishing dreams always came with the pains, not by eliminating the pains. The participants were instructed to write any kinds of dissatisfaction related to taekwondo on one side of the paper. They were also informed that complaints to coaches, uncomfortable peer relationship, irritation, and anger would not share to anyone. The papers were torn down and dumped.

\section{Fourth session activity}

The goal of the fourth session was to contact with the present moment by observing thoughts and experiences about anger and irritation. In other words, when they faced dissatisfaction and irritation, they defused the present thoughts, feelings, and physical senses so that they could understand being present in a flexible way. For the mindfulness activity, gradual relaxation routine and the palm meditation took place. For acceptance and commitment, floating a leaf was conducted to defuse present thoughts, feelings, and physical senses, and realize them. This is one of the awareness trainings with imagining a leaf floating along a stream to be aware of one's personal experiences such as thoughts and emotions. This helped cognitive de-fusion much. Instead of using judgmental language, these techniques encouraged flexible reactions so that they could contact the present moment and place. The goal of this session was not to change, avoid or fight against things in mind, but rather to observe as if watching a movie or TV. Observation required watching any changes as they were through realizing breathing and kinesthetic senses such as muscular movement. If, in the process, the mind was drifting away, they should follow its way gently. They imagined that they sit by the stream and placed their concerns, worries on the fallen leaves calmly, and they watched the leaves gradually drifting out of sight. The participants practiced this with lying down in circle on a taekwondo mat. In the fourth session, they were assigned to write a journal of one mind at once by observing personal experiences such as thoughts or emotions with various mindfulness activities in order to have cognitive defusion. The participants' mindfulness could be seen through their experiences of eating, daily life, physical activity, medication, studying, and so on. In particular, due to eating orange meditation, mindfulness was realized while eating. Walking and breathing were also mindful.

\section{Fifth session activity}

The goal of the fifth session was to experience the present moment as it was by staying away from the thoughts and emotions about themselves. This was to experience inner feelings as they were by nonjudgmental awareness, being present, and contacting the present experiences.

Breath meditation and breath-counting meditation were used for mindfulness activities. Breath-counting meditation was to count slowly a set of inhaling and exhaling with using the lower abdomen. For example, inhale-exhale one, inhale-exhale two, inhale-exhale three, ... inhale-exhale ten. When inhaling, they imagined they breathed in the world's clearest and purest air, and when exhaling, all the dirty energy and negative thoughts were escaping through their nose. This activity helped them think the new air purified the body and cleaned the heart through respiration.

After analyzing the moods, desires and thoughts about themselves as a taekwondo player, negative factors as dissatisfaction and irritation were expressed. Based on this result, under the theme of the one's attitude toward anger, it was explained how to handle anger. First of all, after acknowledging anger toward taekwondo training, they should accept the fact that they were angry. And 
when it is hard to realize their anger, they should take some measures such as breath meditation, breath-counting meditation, and counting numbers backwards (from 20 to 1 ) so that they acknowledged their anger, which would disappear soon.

For acceptance and commitment activities, they were asked to mention what was good and bad about their taekwondo skills. They repeated the word 'milk' as fast as they could for $45 \mathrm{sec}$ in order to help them understand that 'good' and 'bad' were judgmental. In addition, they wrote down how they saw themselves as a taekwondo athlete, and picked up a worst word in the writing, and shouted that word out loud for 20 to $45 \mathrm{sec}$.

Analysis on the thoughts, desires, and feelings as a taekwondo player and for taekwondo training showed that both positive and negative factors existed at the same time. For the training, it was described most unpleasant, irritating, and bothering. The reason was that the training time was increased in length and quantity. The 2-hr training after classes during the academic year was changed to both the morning and afternoon during the winter break.

\section{Sixth session activity}

The goal of the sixth session was to accept and acknowledge anger through meditation, Welcoming the beggar, for which the participants read about welcoming the beggar and talked about it after doing ACT such as the relaxation routine, breath-counting meditation, and the body scan. Body scan was to lie down on the ground and feel their body and breathing from which they felt the whole body from head to toe, and then started to feel the pressure of some body parts like a heap that touched the floor.

Welcoming the beggar had two versions. One was welcoming the beggar and buying the beggar bread and the other one was kicking out the beggar. Although the bakery owner might not be happy to have the beggar as a customer, he or she should accept the beggar as a customer. Likewise, Anger was not a welcoming guest, but we could accept it as a guest who was just dropping by.

After that, they were instructed to remember the anger from the taekwondo training, and acknowledge the anger. In addition, they remembered pleasant memories from recent good matches. As a result, they thought of some compliments from their parents and coaches. Especially, compliments from the coaches were mostly about Taekwondo skills. And they were asked to write two separate things: (a) their most successful match and their feelings about it, and (b) what they thought when the feelings arose then. As a result, most of them wrote positive comments about their coach's compliments. Good matches brought good feelings and pleasure. However, the thoughts before the match varied.

\section{Seventh session activity}

The goal of the seventh session was to understand the importance of value-oriented life and the function of a goal that brought health life. For mindfulness, there were the relaxation routine, breath-counting meditation, and a finding numbers game. The finding numbers game used a grid sheet with numbers from 0 to 99, and then found numbers in order within $60 \mathrm{sec}$. By doing so, they could come closer to self-value realization through acceptance and commitment experience.

For acceptance and commitment activities, the story between a bus driver and a passenger helped them understand willingness and value selection. In order to select committed value, writing their epitaph was exercised. First, they were instructed to write a condolatory address that they wished to hear from their families or friends. They imagined that they could see what their families or friends really thought, and how they would describe what kind of taekwondo player they were in their childhood.

As a result, they wanted to be remembered as a great taekwondo player. They were also instructed to write a letter for themselves to realize what their goal was to achieve the true value of taekwondo and how they should love and adore themselves. Unlike the sixth session, in the letters, difficulties and frustration of taekwondo training did not reveal. They had their own dreams, and understood what they had to do to accomplish their goals, what attitude they needed, and what to do with their stamina, injury, and training.

\section{Eighth session activity}

Lastly, the eighth session was to see what values they have made despite of young age, and what values they should have. For mindfulness, relaxation routine and breath meditation were conducted. At the end of the session, affection meditation was also conducted, using Tapping, one of the emotional freedom technique, with performing a taekwondo skill.

For acceptance and commitment activities, a comparison with a go stone and a go board was explained to understand commitment of the goal and the obstacles in the valuable life. The go stone meant a perceived self, and their emotion, thoughts, and past, and so on. The go board represented the whole which could see, obtain, and contact all the go stones. Following-up, they were asked which one they would like to choose between them. Also, a story of the swamp during backpacking travel indicated that the swamp meant various difficulties in the competitions and tournaments when they went for their goal as a taekwondo player. That is, we jumped in pain because we liked it. Painful and intensive 
training existed ahead in the way to accomplish the valuable goal. The thing they needed when facing obstacles was to endure the training and then set the direction again.

For discovering the values, they were asked to determine importance, present performance, and priorities in the categories of human relationship, family, school life, taewondo, and health. Taekwondo and health were mostly ranked as the first or the second.

\section{Empirical assessment of the activities}

After assessing each session's activities for their feelings and lessons after each session, the activities, such as walking meditation, a bus driver and a passenger activity, and writing a letter to the self, showed the highest (mean, 4.75). Subsequently, a finding numbers' game, breath meditation, Eating orange meditation, Kim's game, and a 'floating a leaf' exercise were in the range of mean from 4.4 to 4.57. Writing about taekwondo training, a 'go stone and go board' activity, affection meditation, breath-counting meditation, holding breath, a 'welcoming the beggars' exercise, feeling the energy of the palm, searching for values in life were in the range of mean from 4.14 to 4.36. Breath meditation, Kim's game, a 'suppressing the white bear' exercise, feeling the energy of the palm, activity sheets, writing an epitaph, passing the swamp were 4 of mean. Tug-of-war with a monster (mean, 3.89) and the body scan (mean, 3.83) were the lowest. An overall evaluation of the activities was 4.26 .

\section{Feeling and emotions after the activities}

Positive feedbacks were shown after each session of the program, whereas negative emotions partially revealed. Therefore, the mean of the overall emotions was 4.39. Concentration and Willingness at the second session and Searching for values in life at the seventh session were the highest as 4.75 of mean. Subsequently, followings were calculated: Strengthening psychological flexibility at the fourth session was 4.73 , Creative helplessness at the first session was 4.67, Understanding for commitment at the sixth session was 4.00, Self-observation at the eighth session was 4.00, Cognitive defusion and Awareness at the third session was 3.80.

\section{Evaluation}

General evaluation for the eight sessions of the ACT showed that it was considered as very effective or considerably effective. Six participants responded that the most positive change was their attitude toward the taekwondo training, followed by changes in thoughts and emotions (anger, irritation). Responses about the programs they wanted to keep doing varied. Eating orange medita- tion, breath meditation, and welcoming the beggar exercise were mentioned most memorable, whereas breathing in sitting or lying was the hardest.

\section{DISCUSSION}

This study was to develop an intervention program based on ACT for youth taekwondo players. The total of eight sessions of the anger acceptance program was developed and provided to nine elementary taekwondo players. Contents analysis was conducted for program activities, activity sheets, assignments, and program evaluations. As a result, the participants eased much psychological inflexibility through ACT, and turned to be value-oriented. The feedback and evaluation after each session supported the results with overall positive reactions from the participants.

Children are instinctive. They are impulsive, and they seek sensation. Therefore, being present seems the easiest thing for them. But, they were not able to focus in the present moment. In reality, they were struggling with a computer game and their taekwondo training. Nevertheless, during the study, it appeared that their goal and value-adding as a taekwondo player were quite high despite of their young age. Still, at the same time, they shared a common ground such as complaints about intensive training, criticism from coaches, and a wish for early dismissal of the winter training.

Intensive training might cause psychological and physical pains to the students. However, the stronger they rejected training, the bigger coaches' pressure was. So, they had to fight against pain and anger. The solution was to encourage their willingness to take the winter training, and for them to accept it openly. ACT helped the participants aware that psychological obstacles and nondefensive contact caused by pursuing their selected values (Harris, 2009; Hayes and Strosahl, 2004). As it was important to pursue values, they were asked to write their epitaph about what kind of player they wished to be remembered. Then, they were asked to choose what kind of actions they would take in the training field. It was because the present moment was here then, whereas a goal was in the future. So, although they were young, they had to judge and decide what was important right now, and they should take appropriate actions for values which is required to take value-oriented actions to reach a goal (Blonna, 2010).

For young athletes, all day training was boring and tiring, but they were not able to avoid it. This process made them not only angry and aggressive, but also suppressed. It was impressive that walking meditation, a bus driver and a passenger activity, and writing a letter to the self received most valuable out of all the ac- 
tivities in each session. Walking meditation made their mind comfortable and to feel the sense of body, which, in other words, did not try to control anger naturally arisen from the hard training. It kept their focus and calmness (Forsyth and Eifert, 2007). That was also the same point of view with mindfulness acceptance commitment approach (MAC). MAC is one of the cognitive behavior programs which combine ACT with Mindfulness meditation. Walking meditation is a kind of the MAC techniques. The walking meditation is to walk with concentrating on steps so that you can focus on the present moment without judgement (Gardner and Moore, 2007). At the same time, it requires mindfulness observation. According to Wilson and DuFrene (2008), intervention of acceptance and mindfulness is necessary when behaviors are passive and stiff. Children's behaviors would be stiff when they wish to avoid the hard taekwondo training. In this context, writing a letter to the beloved-self was a great way of learning acceptance in order to realize values.

It is not necessary to have the desirable emotions to execute value-oriented behaviors (Follette et al., 2007). It is possible that they get angry and aggressive by a high intensive training provided by coaches. However, the point is to realize its intention. In this study, through various mindfulness activities, it turned out that young taekwondo players found the value and commitment about taekwondo while they were struggling with fights against anger. The intended ACT that pursued in this study helped analyze their anger and fight, and helped them find values and commitment for taekwondo while struggling with pain. It is important to maintain the value even after the study (Ciarrochi and Bailey, 2008).

In sum, this study is meaningful as it applied ACT to the sports and the young taekwondo athletes. Also, its goal aimed for anger management of children, and it proved it was helpful. However, there were difficulties during researching. In the future, children's concentration span should be considered more. A small and closed place to do activities will be better than a wide place like a gym, which could help children focus more. Mindfulness activities and diverse metaphoric stories in the program were enough to catch children's attention. Therefore, if the metaphoric stories are modified strategically to each sport, this ACT program will be applicable to other sports as well.

\section{CONFLICT OF INTEREST}

No potential conflict of interest relevant to this article was reported.

\section{ACKNOWLEDGEMENTS}

This study was spported by the National Research Foundation of Korea (NRF-2013S1A2A1A01034591).

\section{REFERENCES}

Ahn J. The effect of taekwondo players' stress decrease on abdominal breathing and meditation program. J Korean Soci Stud Phy Edu 2003; 8.2:172-187.

Beck R, Fernadez E. Cognitive-behavioral therapy in the treatment of anger: a meta-analysis. Cogn Ther Res 1998;22:63-74.

Benson H. The relaxation response. New York: Williams Morrow; 1975.

Blonna R. Stress less, live more: how acceptance and commitment therapy can help you live a busy yet balanced life. Oakland (CA): New Harbinger Publications; 2010.

Chen X, Rubin KH, Li B. Social and school adjustment of shy and agressive children in china. Dev Psychopathol 1995:7:337-349.

Ciarrochi J, Bailey A. A CBT-practitioner's guide to ACT: how to bridge the gap between cognitive behavioral therapy and acceptance and commitment therapy. Oakland (CA): New Harbinger Publications; 2008.

Follette V, Pistorello J. Hayes S. Finding life beyond trauma: using acceptance and commitment therapy to heal from post-traumatic stress and trauma-related proble. Oakland (CA): New Harbinger Publications; 2007.

Forsyth JP, Eifert GH. The mindfulness and acceptance workbook for anxiety. Oakland (CA): New Harbinger; 2007.

Gardner FL, Moore ZE. The psychology of enhancing human performance: The mindfulness-acceptance-commitment (MAC) approach. New York: Springer Publishing Company; 2007.

Greco LA, Hayes SC. Acceptance \& mindfulness treatments for children \& adolescents: a practitioner's guide. Oakland (CA): New Harbinger Publications; 2008.

Han K, Son S. Relation of primary school student's taekwondo practice and aggression. J Sport Leis Stud 2003;20:905-922.

Harris R. ACT made simple: an easy-to-read primer on acceptance and commitment therapy. Oakland (CA): New Harbinger; 2009.

Hayes SC, Strosahl KD. A practical guide to acceptance and commitment therapy. New York: Springer; 2004.

Hayes SC, Storsahl KD, Wilson KG. Acceptance and commitment therapy: an experiential approach to behavior change. New York; Guilford Press; 1999.

Heffner M, Sperry J, Eifert GH, Detweiler M. Acceptance and commitment therapy in the treatment of an adolescent female with anorexia 
nervosa: a case example. Cogn Behav Pract 2002;9(Pt 3):232-236.

Huesmann LR, Eron LD. Cognitive processes and the persistence of aggressive behavior. Aggress Behav 1984;10:243-251.

Keng SL, Smoski MJ, Robins CJ. Effects of mindfulness on psychological health: a review of empirical studies. Clin Psychol Rev 2011;31:10411056.

Kim GP. Relationship between the type of taekwondo training hall program and spiritual power. Korean J Phys Edu 2005;44:543-552.

Kim J, Suh W, Kim S, Gopalan H. Coping strategies to manage acculturative stress: meaningful activity participation, social support, and positive emotion among Korean immigrant adolescents in the USA. Int J Qual Stud Health Well-being 2012;7:1-10.

Kim JH, Kim GP. The relationship between taekwondo training type of physical self-efficacy and mental of martial art. Korean J Phys Edu 2000;39:34-47.

Lakes KD, Hoyt WT. Promoting self-regulation through school-based martial arts training. J Appl Dev Psychol 2004;25:283-302.

Lee GH. Relationship of taekwondo training to sociability development and mental health among american elementary schoolers. J Korean Alliance Martial Art 2010;12:205-220.

Lee GH, Song HS. The relationship study between taekwondo training and self-concept development among elementary school children. Korean J Phys Edu 2006;45:121-129.

Luoma JB, Hayes SC, Walser RD. Learning ACT: An acceptance \&commitment therapy skills-training manual for therapists. Oakland (CA): New Harbinger Publications; 2007.

Moore D, Wilson KG, Wilson DM, Murrell AR, Roberts M, Merwin R.
Treating at-risk youth with an in-school acceptance and commitment training program. In: Annual meeting of the Association for Behavior Analysis; 2003 May; San Francisco (CA), USA.

Rempel KD. Mindfulness for children and youth: a review of the literature with an argument for school-based implementation. Can J Couns Psychother 2012;46:201-220.

Song HJ, Son CN. The effects of acceptance and commitment therapy on anger, stress, and binge eating behavior of the binge eating disorder-prone college students. Korean J Health Psychol 2011;16:15-27.

Sukhodolsky DG, Kassinove H, Gorman BS. Cognitive-behavioral therapy for anger in children and adolescents: A meta-analysis. Aggress Violent Behav 2004;9:247-269.

Wicksell RK, Dahl J, Magnusson B, Olsson GL. Using acceptance and commitment therapy in the rehabilitation of an adolescent female with chronic pain: a case example. Cogn Behav Pract 2005;12:415-423.

Wilkowski BM, Robinson MD. The cognitive basis of trait anger and reactive aggression: an integrative analysis. Pers Soc Psychol Rev 2008;12: 3-21.

Wilkowski BM, Robinson MD, Troop-Gordon W. How does cognitive control reduce anger and aggression? The role of conflict monitoring and forgiveness processes. J Pers Soc Psychol 2010;98:830-840.

Wilson KG, DuFrene T. Mindfulness for two: an acceptance and commitment therapy approach to mindfulness in psychotherapy. Oakland (CA): New Harbinger; 2008.

Zettle RD, Rains JC, Hayes SC. Processes of change in acceptance and commitment therapy and cognitive therapy for depression: a mediation reanalysis of Zettle and Rains. Behav Modif 2011;35:265-283. 